\title{
High-sensitivity C-reactive protein concentrations among patients with and without diabetes in a multiethnic population of Singapore: CREDENCE Study
}

\author{
Rinkoo Dalan' \\ Michelle Jong' \\ Siew-Pang Chan ${ }^{4,5}$ \\ Robert Hawkins ${ }^{2}$ \\ Robin Choo' \\ Brenda Lim' \\ May L Tan ${ }^{3}$ \\ Melvin KS Leow ${ }^{1,6}$ \\ 'Department of Endocrinology, \\ ${ }^{2}$ Department of Laboratory Medicine, \\ ${ }^{3}$ Health Enrichment Centre, Tan Tock \\ Seng Hospital, Singapore; ${ }^{4}$ School of \\ Business, SIM University, Singapore; \\ ${ }^{5}$ Faculty of Health Sciences, La Trobe \\ University, Australia; ${ }^{6}$ Singapore \\ Institute for Clinical Sciences, Brenner \\ Centre for Molecular Medicine, \\ Singapore
}

This article was published in the following Dove Press journal: Diabetes, Metabolic Syndrome and Obesity:Targets and Therapy 19 June 2010

Number of times this article has been viewed
Objectives: To determine whether high-sensitivity C-reactive protein (hs-CRP) concentrations differ between Chinese, Malays, and Indians with and without type 2 diabetes mellitus and to look for an association with demographic, metabolic and therapeutic variables.

Methods: Phase 1: We retrieved records of 50 Chinese, 51 Malay, and 67 Indian individuals who had routine health screening blood tests. Phase 2: We recruited 111 Chinese, 68 Malays, and 67 Indians with type 2 diabetes mellitus and measured their hs-CRP in addition to standard laboratory tests.

Results: Phase 1: The median hs-CRP was $0.6 \mathrm{mg} / \mathrm{L}(0.2-6.2)$ in Chinese, $1.2 \mathrm{mg} / \mathrm{L}$ (0.2-7.9) in Malays, and $1.9 \mathrm{mg} / \mathrm{L}(0.2-10.0)$ in Indians. The Indians had higher hs-CRP compared to Chinese $(P<0.05)$ when adjusted for age, sex, body mass index (BMI), lipids, blood pressure, and smoking, and a significant correlation was seen between female sex, smoking status, fasting glucose and triglyceride concentration, and hs-CRP in all three ethnicities. Phase 2: The median hs-CRP was $1.2 \mathrm{mg} / \mathrm{L}(0.2-9.9)$ in Chinese, $2.2 \mathrm{mg} / \mathrm{L}(0.2-9.0)$ in Malays, and $2.3 \mathrm{mg} / \mathrm{L}$ $(0.2-9.8)$ in Indians. Indians had higher hs-CRP when compared to Chinese $(P<0.05)$ and a significant correlation was seen between BMI, female gender, diabetes, and the use of metformin and hs-CRP in all three ethnicities $(P<0.05)$ when adjusted for the above variables and use of aspirin, angiotensin-converting enzyme inhibitor/angiotensin receptor blockers (ACE-I/ARB), statin, metformin, rosiglitazone, sulfonylurea, glinides, acarbose, and insulin.

Conclusion: hs-CRP concentrations are significantly higher in Indians compared to the Chinese (in both the diabetic and nondiabetic individuals) after adjustment for the various demographic, metabolic, and therapeutic variables.

Keywords: C-reactive protein, ethnicity, diabetes mellitus, cardiovascular disease

\section{Introduction}

Singapore is a small and densely populated country of 4.59 million people. There are three major ethnic groups: 75\% Chinese, 13.7\% Malays, 8.7\% Indians (South Asians who trace their ancestry from the Indian subcontinent), and 2.6\% others (http://www. singstat.gov.sg).

In Singapore, it has been seen that Indians are at increased risk of developing coronary heart disease (CHD) when compared to other populations. ${ }^{1}$ On average, Indians are at three-fold risk and Malays two-fold risk when compared to Chinese. Previous cross-sectional studies have shown that the greater susceptibility of Indians to CHD is not explained by higher incidence of the traditional risk factors
Correspondence: R Dalan

Department of Endocrinology, Tan Tock Seng Hospital, I I Jalan Tan Tock Seng, Singapore 308433

Email rinkoo_dalan@ttsh.com.sg 
(cigarette smoking, hypertension or hypercholesterolemia) ${ }^{2}$ or by hyperhomocysteinemia. ${ }^{3}$

Indians have been shown to have a high risk of developing CHD with or without diabetes. ${ }^{4-6} \mathrm{High}$-sensitivity C-reactive protein (hs-CRP) is one of the strongest univariate predictors of risk of cardiovascular events in both men and women, ${ }^{5-8}$ and higher hs-CRP concentrations have been reported for Asian Indians when compared to other populations in various studies. ${ }^{5,9-11}$ However, there is presently still no published data of a comparison of hs-CRP concentrations in the three major ethnic groups of Singapore.

In this study, we sought to determine if hs-CRP was different in the three racial groups, regardless of whether they had diabetes.

\section{Patients and methods}

Phase 1: We selected 168 consecutive individuals (50 Chinese, 51 Malays, and 67 Indians) from our health screening center who had a serum hs-CRP measured. We looked retrospectively into their records for their demographic data (age, sex), smoking history, body mass index (BMI), blood pressure, hs-CRP concentration, fasting lipids and glucose concentrations.

The patients had their blood drawn after a 10-hour overnight fast. Serum glucose concentration was measured by glucose oxidase using the oxygen rate method. Serum lipids were measured using the standard coupled enzymatic methods. Low-density lipoprotein cholesterol (LDL-C) was calculated by using the Friedewald equation. Therefore, when the fasting triglyceride concentration was above $4.5 \mathrm{mmol} / \mathrm{L}$, the LDL-C was not estimated. We excluded patients with a fasting glucose of $>7.0 \mathrm{mmol} / \mathrm{L}$ or a history of type 2 diabetes mellitus. Smoking history and ethnicity was self reported by the individuals.

Phase 2: We recruited 246 consecutive individuals with type 2 diabetes mellitus (111 Chinese, 68 Malays, and 67 Indians) from our Diabetes and Endocrine Centre and included an hsCRP test to their routine blood draw. We reviewed their records for demographic data (age, sex), smoking history, BMI, glycated hemoglobin (HbAlc), lipid profile, blood pressure, and medication history such as antidiabetic agents (metformin, sulfonylurea, rosiglitazone, acarbose, glinide or insulin), angiotensin-converting enzyme inhibitor (ACE-I), angiotensin receptor blocker (ARB), aspirin, and statin. All the participants signed an informed written consent. The study was ethically approved by our institutional review board.

The patient's smoking history was based on self reports. Ethnicity classification was based on their National Identification Cards. HbA1c was checked by immunoturbidometric measurement on the Beckman Coulter Synchron LX ${ }^{\circledR} 20$ (Beckman Coulter, Inc., Brea, CA, USA) clinical chemistry analyzer in our laboratory. Serum lipids were measured after a 10-hour overnight fast and was also measured using standard coupled enzymatic methods. LDL-C was calculated by the Friedewald equation. hs-CRP was measured by near infrared particle immunoassay. All values of hs-CRP which were higher than $10 \mathrm{mg} / \mathrm{L}$ were excluded from the study because such an elevation of hs-CRP might also result from a possible systemic infection. As we do not have information regarding the income and standard of living for every individual, we used government subsidies as a surrogate marker. A patient who received government subsidies for their health care (subsidized patients) was deemed to have a lower socioeconomic status than a patient who received no subsidy (private patients).

The distribution of hs-CRP in this study was very highly skewed to the left (see Figure 1). Robust regression analysis was applied to analyze the data. Unlike the conventional multiple regression model based on ordinary least squares (OLS), the proposed robust model is designed to accommodate outlying observations which are often observed with skewed variables. ${ }^{12,13}$ Estimated with iterative reweighted least squares (IRWLS) algorithm, the proposed robust model was able to generate more reliable estimates about the influence of ethnicity on hs-CRP, after adjusting for all relevant variables in Phase 1, Phase 2 and in both groups combined together. The proposed robust model has several advantages over the conventional approach in data analysis. Firstly, it analyzes the skewed outcome directly without the need to perform back-transformation for interpretation. This is desirable because arithmetic transformation may not necessarily induce normality in the skewed outcome. Secondly, it does not discard

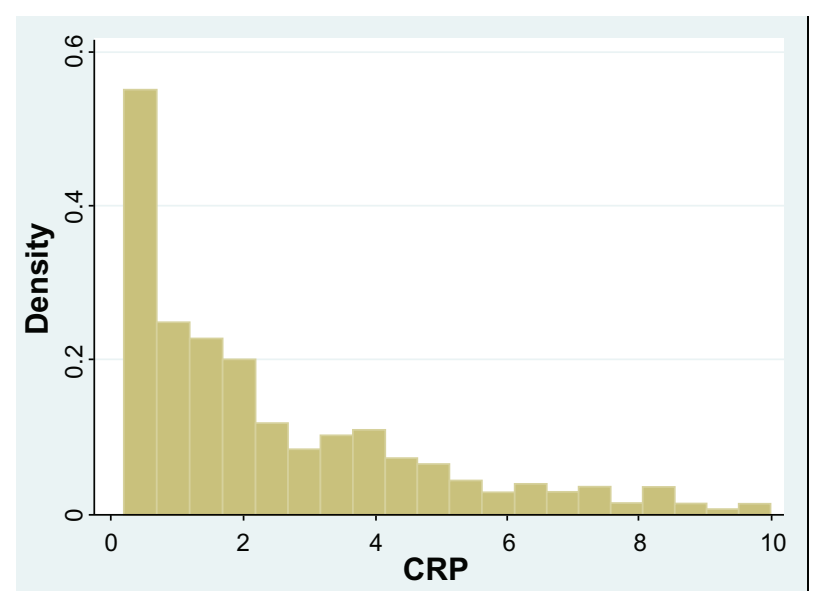

Figure I Histogram showing that the high-sensitivity C-reactive protein (hs-CRP) levels were skewed to the left in the entire population. 
any observations in the process even if they are confirmed outliers. Lastly, it does not impose any strict distributional assumption on the outcome like generalized linear model (GLM), as there is no precise information about the outcome's probabilistic characteristics. This in turn offers much flexibility and convenience in data analysis. ${ }^{12,13}$ Analyzed with Stata 10.0 (Stata Corp, College Station, TX, USA), all statistical tests were conducted at $5 \%$ level of significance.

\section{Results}

The baseline characteristics of patients with or without diabetes of each ethnic group are provided in Table 1 and Table 2. In Phase 1, the median hs-CRP was $0.6 \mathrm{mg} / \mathrm{L}$ $(0.2-6.2)$ in Chinese, $1.2 \mathrm{mg} / \mathrm{L}(0.2-9.9)$ in Malays, and $1.9 \mathrm{mg} / \mathrm{L}(0.2-10.0)$ in Indians (Figure 2A). In Phase 2, the median hs-CRP was $1.2 \mathrm{mg} / \mathrm{L}(0.2-9.9)$ in Chinese, $2.2 \mathrm{mg} / \mathrm{L}$ $(0.2-7.9)$ in Malays, and $2.3 \mathrm{mg} / \mathrm{L}(0.2-9.8)$ in Indians (Figure 2B). The number of current smokers was higher in Phase 1 when compared to Phase 2, likely due to counseling measures to stop smoking in patients with diabetes mellitus. There were generally more subsidized patients when compared to private patients in all ethnicities.
In the Indian subgroup, there were more private patients (38.8\%) when compared to the Chinese $(28.8 \%)$ and Malays (10.3\%). The mean BMI was higher in the Malays $\left(30.4 \mathrm{~kg} / \mathrm{m}^{2}\right)$ when compared to the Indians $\left(26.7 \mathrm{~kg} / \mathrm{m}^{2}\right)$ and the Chinese in patients with diabetes mellitus $\left(26.3 \mathrm{~kg} / \mathrm{m}^{2}\right)$. The mean systolic and diastolic blood pressure was comparable in all three ethnicities but was higher in those with diabetes. The mean $\mathrm{HbA1} \mathrm{c}$ was highest in the Malays $(8.5 \%)$ when compared to the Indians $(8.0 \%)$ and Chinese $(7.9 \%)$. The mean fasting glucose in patients without diabetes was highest in the Indians $(5.5 \mathrm{mmol} / \mathrm{L})$ when compared to the Chinese $(4.9 \mathrm{mmol} / \mathrm{L})$ and Malays $(5.2 \mathrm{mmol} / \mathrm{L})$. The mean total triglyceride was higher and the mean high-density lipoprotein (HDL) cholesterol was lower in patients with diabetes. The lower concentrations of LDL-C and total cholesterol in patients with diabetes may be treatment-related as $82.5 \%$ of them were on statins. The use of various drugs in patients in various ethnic groups was comparable.

We saw a significant positive association of hs-CRP in patients with diabetes mellitus $(P=0.03)$, female sex $(P=0.001)$, Indian ethnicity $(P<0.001)$, and BMI $(P<0.001)$ after adjusting for smoking status, age, sex,

Table I Baseline characteristics

\begin{tabular}{|c|c|c|c|c|c|c|c|c|}
\hline & $\begin{array}{l}\text { All } \\
\text { Phase I }\end{array}$ & $\begin{array}{l}\text { All } \\
\text { Phase } 2\end{array}$ & $\begin{array}{l}\text { Chinese } \\
\text { Phase I }\end{array}$ & $\begin{array}{l}\text { Chinese } \\
\text { Phase } 2\end{array}$ & $\begin{array}{l}\text { Malay } \\
\text { Phase I }\end{array}$ & $\begin{array}{l}\text { Malay } \\
\text { Phase } 2\end{array}$ & $\begin{array}{l}\text { Indian } \\
\text { Phase I }\end{array}$ & $\begin{array}{l}\text { Indian } \\
\text { Phase } 2\end{array}$ \\
\hline Total no. $n$ & 168 & 246 & 50 & 111 & 51 & 68 & 67 & 67 \\
\hline $\begin{array}{l}\text { Mean age - years } \\
\text { (SD) }\end{array}$ & $45(13)$ & $55.8(I 3)$ & $50(9)$ & $58(13)$ & $39(15)$ & $52(11)$ & $46(13)$ & $57(13)$ \\
\hline Males - n (\%) & 90 (53.5\%) & 140 (56.9\%) & $22(44 \%)$ & $64(57.7 \%)$ & 27 (52.9\%) & $36(52.9 \%)$ & $44(65.6 \%)$ & 40 (59.7\%) \\
\hline Smokers - n (\%) & $26(13.6 \%)$ & 24 (9.7\%) & $4(8 \%)$ & $10(9 \%)$ & $14(27.4 \%)$ & $5(7 \%)$ & $16(23.8 \%)$ & $9(13.4 \%)$ \\
\hline Socioeconomic status: & $168(100 \%)$ & $65(26.4 \%)$ & $50(100 \%)$ & $32(28.8 \%)$ & $51(100 \%)$ & $7(10.3 \%)$ & $67(100 \%)$ & $26(38.8 \%)$ \\
\hline Private - n (\%) & & & & & & & & \\
\hline Mean BMI (kg/m²) & $25.1(5.4)$ & $27.6(5.3)$ & $23.3(4.5)$ & $26.3(4.7)$ & $26.3(6.4)$ & $30.4(5.5)$ & $25.6(4.8)$ & $26.7(4.8)$ \\
\hline $\begin{array}{l}\text { Mean systolic blood } \\
\text { pressure (SD) }\end{array}$ & I25.I (I2.8) & $135.0(19.8)$ & $125.7(\mid 3.7)$ & $135.8(20.6)$ & $125.1(\mid 2.1)$ & $136.5(17.5)$ & $124.6(12.7)$ & $132.3(20.7)$ \\
\hline $\begin{array}{l}\text { Mean diastolic blood } \\
\text { pressure (SD) }\end{array}$ & $78.7(10.1)$ & $73.4(10.3)$ & $79.5(8.9)$ & $73.7(10.6)$ & $76.9(10.5)$ & $73.1(9.7)$ & $79.5(10.5)$ & $73.1(10.3)$ \\
\hline HbAlc (\%) & ND & $8.1(1.7)$ & ND & $7.9(1.8)$ & ND & $8.5(1.7)$ & ND & $8.0(1.7)$ \\
\hline $\begin{array}{l}\text { Mean fasting glucose } \\
\mathrm{mmol} / \mathrm{L} \text { (SD) }\end{array}$ & $5.2(1.2)$ & ND & $4.9(0.5)$ & ND & $5.2(0.7)$ & ND & $5.5(1.8)$ & ND \\
\hline $\begin{array}{l}\text { Mean total cholesterol } \\
\mathrm{mmol} / \mathrm{L}(\mathrm{SD})\end{array}$ & $5.3(1.0)$ & $4.6(1.2)$ & $5.7(1.2)$ & $4.6(1.2)$ & $5.3(1.04)$ & $4.9(1.3)$ & $5.1(0.9)$ & $4.2(0.7)$ \\
\hline $\begin{array}{l}\text { Mean HDL-C mmol/L } \\
\text { (SD) }\end{array}$ & I.3 (0.4) & I.I (0.4) & I.5 (0.4) & I. $2(0.5)$ & I.3 (0.3) & I.I (0.3) & I.I (0.7) & I.0 (0.3) \\
\hline $\begin{array}{l}\text { Mean LDL-C mmol/L } \\
\text { (SD) }\end{array}$ & $3.5(0.8)$ & $2.7(0.9)$ & $3.6(0.9)$ & $2.7(0.8)$ & $3.5(0.9)$ & $3.1(1.1)$ & $3.5(0.8)$ & $2.6(0.6)$ \\
\hline $\begin{array}{l}\text { Mean triglyceride } \mathrm{mmol} / \mathrm{L} \\
\text { (SD) }\end{array}$ & $1.2(1.0)$ & $1.4(0.9)$ & $1.2(1.4)$ & $1.4(0.9)$ & I.I (0.9) & $1.7(1.0)$ & $1.2(0.7)$ & $1.4(0.9)$ \\
\hline Mean hs-CRP mg/L & $2.04(2.06)$ & $2.59(2.34)$ & $1.37(1.60)$ & $2.02(2.18)$ & $1.85(1.70)$ & $3.05(2.38)$ & $2.69(2.40)$ & $3.07(2.38)$ \\
\hline $\begin{array}{l}\text { Median hs-CRP (25\%-75\%) } \\
\mathrm{mg} / \mathrm{L}\end{array}$ & $1.2(0.5-3.1)$ & $1.9(0.7-4.0)$ & $0.6(0.2-2.2)$ & $1.2(0.3-3.3)$ & $1.2(0.6-2.4)$ & $2.2(1.1-4.3)$ & $1.9(0.8-4.0)$ & $2.3(1.2-4.2)$ \\
\hline
\end{tabular}

Abbreviations: BMI, body mass index; HbAIc, glycated hemoglobin; HDL-C, high-density lipoprotein cholesterol; hs-CRP, high-sensitivity C-reactive protein; LDL-C, lowdensity lipoprotein cholesterol; n, number; ND, not done; SD, standard deviation. 
Table 2 Percentage of patients on various drugs for the treatment of diabetes mellitus and others in Phase 2

\begin{tabular}{lllll}
\hline & Phase 2 (AII) & Chinese & Malays & Indians \\
\hline Total no (\%) & $246(100 \%)$ & III (I00\%) & $68(100 \%)$ & $67(100 \%)$ \\
Aspirin & $95(38.6 \%)$ & $37(33.3 \%)$ & $27(39.7 \%)$ & $31(46.3 \%)$ \\
Statin & $203(82.5 \%)$ & $82(73.9 \%)$ & $6 I(89.7 \%)$ & $60(89.6 \%)$ \\
ACE-I/ARB & $164(66.7 \%)$ & $70(63.0 \%)$ & $48(70.6 \%)$ & $46(68.7 \%)$ \\
Metformin & $191(77.6 \%)$ & $8 I(73.0 \%)$ & $57(83.8 \%)$ & $53(79.1 \%)$ \\
Rosiglitazone & $22(8.9 \%)$ & $14(12.6 \%)$ & $2(2.9 \%)$ & $6(8.9 \%)$ \\
Sulfonylurea & II6 (47.2\%) & $57(51.4 \%)$ & $31(45.6 \%)$ & $28(41.8 \%)$ \\
Acarbose & $12(4.9 \%)$ & $5(4.5 \%)$ & $5(7.4 \%)$ & $2(3.0 \%)$ \\
Glinides & I (0.4\%) & $1(0.9 \%)$ & $0(0 \%)$ & $0(0 \%)$ \\
Insulin & $I I 2(45.5 \%)$ & $40(36 \%)$ & $40(58.8 \%)$ & $32(47.8 \%)$ \\
\hline
\end{tabular}

Abbreviations: ACE-I/ARB, angiotensin-converting enzyme inhibitor/angiotensin receptor blockers.

ethnicity BMI, blood pressure, and cholesterol profile (Figure 3, Supplementary Table 1).

Amongst individuals in Phase 1, we saw a statistically significant association between hs-CRP and Indian ethnicity ( $P=0.05)$, BMI $(P<0.001)$, female sex $(P=0.005)$, fasting glucose $(P=0.047)$, smokers $(P=0.013)$, and fasting triglyceride concentrations $(P=0.08)$ (Supplementary Table 2$)$. By performing a robust regression analysis in patients with diabetes, we saw a significant positive association of hs-CRP with Indian ethnicity $(P<0.001)$, female sex $(P=0.02)$, BMI $(P<0.001)$, and a negative association with the use of metformin $(P=0.002)$ (Supplementary Table 3$)$. The mean hs-CRP concentrations were higher in the Malays as compared to the Chinese but lower than the Indians. However, after adjusting for the various factors, this was not statistically significant.

\section{Discussion}

The ethnic diversity in Singapore reflects three genetic roots in Asia (the most populous nations in the world), mainly China, India, and Malaysia/Indonesian. Our paper examines the ethnic differences in hs-CRP among a hospital

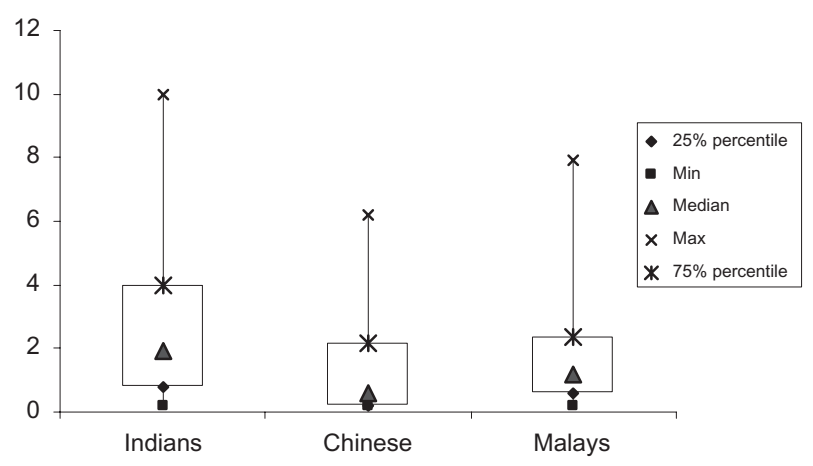

Figure 2A Phase I: high-sensitivity C-reactive protein (hs-CRP) concentrations in individuals without diabetes mellitus.

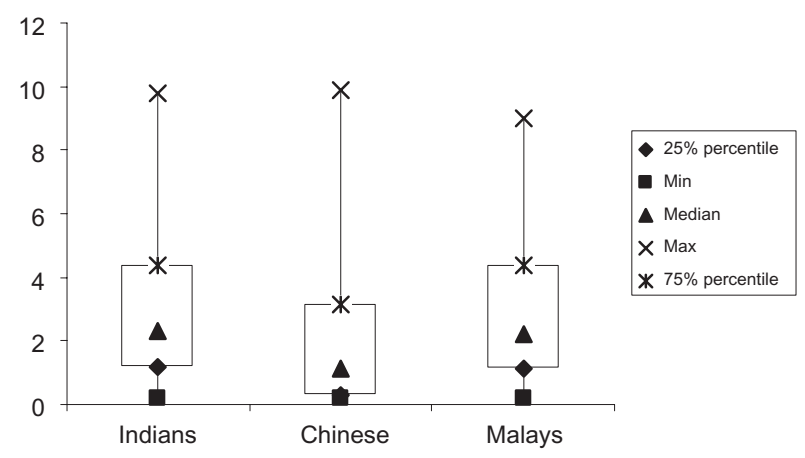

Figure 2B Phase 2: high-sensitivity C-reactive protein (hs-CRP) concentrations in individuals with diabetes mellitus.

sample of Singaporean subjects with and without type 2 diabetes mellitus. In our study of the multiethnic population of Singapore (comprising Chinese, Malays, and Indians) hs-CRP concentrations were found to be higher in Indians when compared to Chinese $(P<0.05)$ even after adjustment for age, sex, BMI, blood pressure, smoking status, and lipid profile regardless of whether the patient had diabetes or not. Our study also shows that hs-CRP concentrations are significantly higher in patients with diabetes when compared to patients without diabetes in all three ethnic groups. This association again is independent of age, sex, BMI, lipid profile, ethnicity, blood pressure, lipid profile, and smoking status. Females also had a significantly higher hs-CRP.

Our data is consistent with what others have found, in that Indians have a higher hs-CRP when compared to other populations in various studies., ${ }^{5,-11}$ In the National Health Survey (of Singapore) 2004, Indians had the highest prevalence of diabetes among the three ethnic groups (15.3\% compared to $11.0 \%$ in Malays and $7.1 \%$ in Chinese). It has also been seen that amongst patients with diabetes, Indians are most ethnically prone to develop CHD followed by the Malays and then the Chinese. ${ }^{14}$ This correlates also with the increased susceptibility of Indians to develop CHD both in populations with or without diabetes mellitus.

Our study shows that hs-CRP concentrations are significantly higher in females when compared to males, which is also consistent with previous observations. ${ }^{15}$ BMI has been known to be associated with high hs-CRP. ${ }^{16}$ Adjusting accordingly for BMI, the hs-CRP is higher in patients with diabetes compared with those without diabetes. The only long-term study to see the effects of antidiabetic drugs on hs-CRP - A Diabetes Outcome Progression Trial (ADOPT) - showed the highest reduction of hs-CRP with rosiglitazone (60\%), followed by metformin $(40 \%)$ and glyburide (20\%). ${ }^{17}$ In our study, hs-CRP was significantly lower in patients with diabetes taking metformin when 


\section{Median CRP in three ethnicties in relationship with BMI}

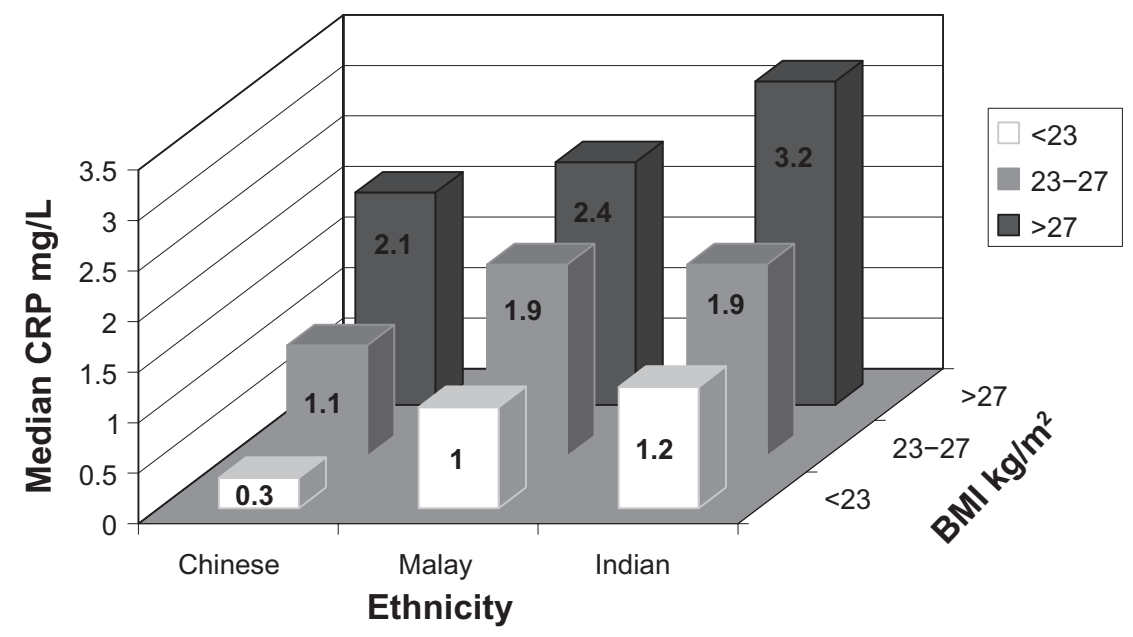

Figure 3 Relationship between median C-reactive protein (CRP) concentrations (mg/L), body mass index (BMI), and ethnicity in the diabetic and nondiabetic multiethnic population of Singapore.

compared to patients without metformin, consistent with its insulin-sensitizing action. Although we would expect rosiglitazone to have a demonstrable effect on hs-CRP reduction, its lack of any statistically significant effect in our study probably lies in the small number of patients on rosiglitazone when compared to the either metformin or sulfonylurea group.

Higher hs-CRP concentrations in Indians has been attributed to higher BMI, higher insulin resistance, and higher frequency of metabolic syndrome; however a meta-analysis has shown that even after adjustment of these variables, the South Asians (Indians) have higher hs-CRP values than people of European descent. ${ }^{18}$ Since our data shows that the hs-CRP concentrations were significantly higher in the Indians compared to Chinese even after adjustment for BMI, blood pressure and lipid profile, it suggested that these features of metabolic syndrome alone may not account for the variation in the hs-CRP concentrations.

Socioeconomic status has also been seen to be associated with hs-CRP concentrations and with the incidence of coronary artery disease. ${ }^{19-21}$ In our study, we adjusted for the socioeconomic status using the financial status of the individuals as a surrogate marker. Even after correction for the socioeconomic status in this manner, it was seen that hs-CRP was higher in the Indians when compared to the Chinese.

Our main limitation is that the sample population is the population visiting the hospital for health screening in Phase 1 and for treatment of diabetes mellitus in Phase 2. Although there is a difference in the socioeconomic status of different ethnic groups, with the median household income being
\$1504 for Malays, \$1882 for Indians, and \$2138 for Chinese as found in our local National Health Survey in 2000, ${ }^{1}$ this status was different in our study as only relatively complicated patients are referred to the hospitals for management. Hence, we used the granting of government subsidies as a surrogate marker for the socioeconomic status though we recognize that this assumption may not be robustly accurate. Our study is also limited by its cross-sectional design, which precludes conclusions regarding any cause-and-effect relationships. Furthermore, we did not adjust for waist circumference, body fat percentage, physical activity and homeostasis model assessment of insulin resistance (HOMA-IR) as these were not done. We also did not have an accurate data collection regarding the exact dose and duration of medications used by our diabetic patients, so we could not adjust for the dose and duration.

The results of our study imply that the Indians have higher hs-CRP concentration which is a marker for low grade inflammation independent of other variables. Therapeutics to target hs-CRP may be warranted in these individuals. As seen in the Justification for the Use of Statins in Primary Prevention: An Intervention Trial Evaluating Rosuvastatin trial (JUPITER), individuals who did not have high LDL-C but who had high hs-CRP concentrations benefited from statin therapy in terms of reduction of cardiovascular events. ${ }^{22}$ If we were to extrapolate that to our study in Phase 1 (healthy individuals) for the Indian subgroup, 18\% would be JUPITER-eligible compared to Chinese (10\%) and Malays (15.6\%). Analysis of the JUPITER trial showed that the achieved hs-CRP concentrations were predictive of event rates irrespective of the lipid endpoint used. They saw a reduction of events by up to $79 \%$ in 
patients who achieved the targets of LDL-C $<1.8 \mathrm{mmol} / \mathrm{L}$ and hs-CRP $<1 \mathrm{mg} / \mathrm{L}$ with statin treatment. ${ }^{23}$ Therapeutics to target more intensive control of other traditional cardiovascular risk factors may also be warranted in this subgroup of patients. For instance, it has been seen that the body fat percentage for a given BMI may be higher in Indians when compared to the Chinese and the Malays. Hence, a lower cutoff for BMI to define obesity has been proposed for the Indians. $^{24}$

We show that Indians have the highest hs-CRP concentrations, and since we know that they also are at the greatest risk of cardiovascular events, it would be logical to demonstrate that reducing hs-CRP concentrations can reduce the cardiovascular risk of this high risk population in line with Bradford Hill's criteria of proving causality. ${ }^{25}$ Future investigations that probe the role of genetic variants and other environmental factors that may influence the concentrations of hs-CRP in the three ethnic groups will also shed more light onto this matter.

\section{Conclusions}

We have found that Indian patients with diabetes have the highest hs-CRP concentration in our ethnically diverse population. This mirrors the higher risk of CHD in the Indians and therapeutics targeting hs-CRP may thus be a priority in addition to intensive control of traditional cardiovascular risk factors.

\section{Author contributions}

RD was the principal investigator and conceptualized the study project, organized the study, collected and analyzed the data, and was involved in the writing of the manuscript. MJ conceptualized the study project, helped in the organization of the study, and in the writing of the final manuscript. $\mathrm{BL}$ and MLT helped in the patient recruitment and in data collection and analysis. SPC and RC were the principal medical statisticians for the statistical analysis. RH and ML helped in the overall conceptualization, organization of study, data processing, and in a critical review of the manuscript.

\section{Acknowledgments}

We would like to thank the Endocrine and Metabolic Society of Singapore (EMSS) for the research grant that funded this study. We would like to thank Ms Hui Ling Tan, Ms Stephania Sim, Ms Linda Koh, Ms Christina Woo, Ms Rahayu Binte Osman and Ms Licia Tan for helping in the data collection and recruitment of patients.

\section{Disclosure}

The authors report no conflicts of interest in this work.

\section{References}

1. Mak KH, Chia KS, Kark JD, et al. Ethnic differences in acute myocardial infarction in Singapore. Eur Heart J. 2003;24:151-160.

2. Hughes K, Yeo PPB, Lun KC, et al. Cardiovascular diseases in Chinese, Malays, and Indians in Singapore: II. Differences in risk factor levels. J Epidemiol Community Health. 1990;44:29-35.

3. Hughes K, Ong C. Homocysteine, folate, vitamin B12, and cardiovascular risk in Indians, Malays, and Chinese in Singapore. $J$ Epidemiol Community Health. 2000;54:31-34.

4. Hughes K. Mortality from cardiovascular diseases in Chinese, Malays and Indians in Singapore, in comparison with England and Wales, USA and Japan. Ann Acad Med Singapore. 1989;18:642-645.

5. Anand SS, Yusuf S, Vuksan V, et al. Differences in risk factors, atherosclerosis, and cardiovascular disease between ethnic groups in Canada: the Study of Health Assessment and Risk in Ethnic groups (SHARE). Lancet. 2000;356:279-284.

6. Lee J, Heng D, Chia KS, Chew SK, Tan BY, Hughes K. Risk factors and incident coronary heart disease in Chinese, Malay and Asian Indian males: the Singapore Cardiovascular Cohort Study. Int J Epidemiol. 2001;30:983-988.

7. Ridker PM, Buring JE, Cook NR, Rifai N. C-reactive protein, the metabolic syndrome, and risk of incident cardiovascular events: an 8-year follow-up of 14,719 initially healthy American women. Circulation. 2003;107:391-397.

8. Koenig W, Sund M, Frohlich M, et al. C-reactive protein, a sensitive marker of inflammation, predicts future risk of coronary heart disease in initially healthy middle-aged men: results from the MONICA (monitoring trends and determinants in cardiovascular disease) Augsburg Cohort Study, 1984 to 1992. Circulation. 1999;99:237-242.

9. Chambers JC, Eda S, Bassett P, et al. C-reactive protein, insulin resistance, central obesity, and coronary heart disease risk in Indian Asians from the United Kingdom compared with European whites. Circulation. 2001;104:145-150.

10. Forouhi NG, Sattar N, McKeigue PM. Relation of C-reactive protein to body fat distribution and features of the metabolic syndrome in Europeans and South Asians. Int J Obes Relat Metab Disord. 2001; 25:1327-1331.

11. Chandalia M, Cabo-Chan AV Jr, Devaraj S, Jialal I, Grundy SM, Abate N. Elevated plasma high-sensitivity C-reactive protein concentrations in Asian Indians living in the United States. J Clin Endocrinol Metab. 2003;88:3773-3776.

12. Rousseuw RJ, LeRoy AM. Robust Regression and Outlier Detection. New York, NY: Wiley; 1987.

13. Hamilton LC. How robust is robust regression? Stata Technical Bulletin. 1991;2:21-26

14. Yeo KK, Tai BC, Heng D, Lee JM, et al. Ethnicity modifies the association between diabetes mellitus and ischemic heart disease in Chinese, Malays and Asian Indians living in Singapore. Diabetologia. 2006; 49:2866-2873.

15. Khera A, McGuire DK, Murphy SA, et al. Race and gender differences in C-reactive protein levels. J Am Coll Cardiol. 2005;46:464-469.

16. Hedgepeth KA, Lloyd-Jones DM, Colvin A, et al. Ethnic differences in C-reactive protein concentrations. Clin Chem. 2008;54:1027-1037.

17. Kahn SE, Haffner SM, Viberti G, et al; for Diabetes Outcome Progression Trial (ADOPT) Study Group. Rosiglitazone decreases C-reactive protein to a greater extent relative to glyburide and metformin over 4 years despite greater weight gain. Diabetes Care. 2010;33:177-183.

18. Nazmi A, Victora CG. Socioeconomic and racial/ethnic differentials of C-reactive protein levels: a systematic review of population based studies. BMC Public Health. 2007;7:212.

19. McDade TW, Lindau ST, Wroblewski K. Predictors of C-reactive protein in the National Social Life, Health, and Aging Project. $J$ Gerontol B Psychol Sci Soc Sci. 2010; Feb 19 [Epub ahead of print]. 
20. Nazmi A, Oliveira IO, Horta BL, Gigante DP, Victora CG. Lifecourse socioeconomic trajectories and C-reactive protein levels in young adults: Findings from a Brazilian birth cohort. Soc Sci Med. 2010;70:1229-1236.

21. Gruenewald TL, Cohen S, Matthews KA, Tracy R, Seeman TE. Association of socioeconomic status with inflammation markers in black and white men and women in the coronary artery risk development in young adults (CARDIA) study. Soc Sci Med. 2009;69:451-459.

22. Ridker PM, Danielson E, Fonseca FA, et al; for JUPITER Trial Study Group. Rosuvastatin to prevent vascular events in men and women with elevated C-Reactive Protein. N Engl J Med. 2008;21:2195-2207.
23. Ridker PM, Danielson E, Fonseca FA, et al; for JUPITER Trial Study Group. Reduction in C-reactive protein and LDL cholesterol and cardiovascular event rates after initiation of rosuvastatin: a prospective study of the JUPITER trial. Lancet. 2009;373:1175-1182.

24. Deurenberg P, Duerenberg-Yap M, Guricci S. Asians are different from Caucasians and from each other in their body mass index/body fat percentage relationship. Obe Rev. 2000;3:141-146.

25. Hill AB. The environment and disease: association or causation? Proc $R$ Soc Med. 1965;58:295-300. 


\section{Supplementary tables}

Supplementary Table I Robust regression in Phase I and Phase 2

\begin{tabular}{|c|c|c|c|c|}
\hline & Coefficient & $P>|t|$ & 95\% lower $\mathrm{Cl}$ & $95 \%$ upper $\mathrm{Cl}$ \\
\hline Phase I & Reference & - & - & - \\
\hline Phase 2 & 0.464 & 0.034 & 0.036 & 0.892 \\
\hline Age (years) & -0.010 & 0.123 & -0.023 & 0.003 \\
\hline \multicolumn{5}{|l|}{ Sex } \\
\hline Males & Reference & - & - & - \\
\hline Female & 0.617 & 0.001 & 0.271 & 0.962 \\
\hline \multicolumn{5}{|l|}{ Race } \\
\hline Chinese & Reference & - & - & - \\
\hline Malay & 0.153 & 0.467 & -0.231 & $0.58 \mathrm{I}$ \\
\hline Indian & 0.893 & $<0.001$ & 0.442 & 1.232 \\
\hline BMI & 0.102 & $<0.001$ & 0.070 & 0.133 \\
\hline Systolic BP (mmHg) & 0.002 & 0.759 & -0.009 & 0.013 \\
\hline Diastolic BP $(\mathrm{mmHg})$ & 0.005 & 0.589 & -0.013 & 0.024 \\
\hline Total cholesterol $(\mathrm{mmol} / \mathrm{L})$ & 0.125 & 0.867 & -1.342 & 1.593 \\
\hline HDL-C (mmol/L) & 0.050 & 0.954 & $-1.64 \mid$ & 1.741 \\
\hline LDL-C (mmol/L) & 0.149 & $0.84 I$ & -1.308 & 1.605 \\
\hline Triglycerides (mmol/L) & 0.432 & 0.224 & -0.265 & 1.129 \\
\hline \multicolumn{5}{|l|}{ Smoking status } \\
\hline Nonsmokers & Reference & - & - & - \\
\hline Smokers & -0.080 & 0.748 & -0.408 & 0.568 \\
\hline Constant & -4.645 & $<0.001$ & -6.604 & -2.687 \\
\hline
\end{tabular}

Abbreviations: BP, blood pressure; Cl, confidence interval; HDL-C, high-density lipoprotein cholesterol; LDL-C, low-density lipoprotein cholesterol.

Supplementary Table 2 Robust regression in Phase I

\begin{tabular}{|c|c|c|c|c|}
\hline & Coefficient & $P$-value & 95\% lower $\mathrm{Cl}$ & $95 \%$ upper $\mathrm{Cl}$ \\
\hline Age & -0.013 & 0.132 & -0.031 & 0.004 \\
\hline \multicolumn{5}{|l|}{ Sex } \\
\hline Male & Reference & - & - & - \\
\hline Female & 0.627 & 0.005 & 0.196 & 1.058 \\
\hline \multicolumn{5}{|l|}{ Race } \\
\hline Chinese & Reference & - & - & - \\
\hline Malay & -0.198 & 0.460 & -0.725 & 0.329 \\
\hline Indian & 0.508 & 0.051 & -0.002 & 1.017 \\
\hline \multicolumn{5}{|l|}{ Smoking status } \\
\hline Nonsmokers & Reference & - & - & - \\
\hline Smokers & -0.708 & 0.013 & -1.267 & -0.149 \\
\hline BMI & 0.100 & $<0.001$ & 0.060 & 0.139 \\
\hline Systolic BP (mmHg) & -0.017 & 0.103 & -0.037 & 0.003 \\
\hline Diastolic BP (mmHg) & 0.014 & 0.308 & -0.013 & 0.041 \\
\hline Fasting glucose (mmol/L) & 0.164 & 0.047 & 0.002 & 0.327 \\
\hline Cholesterol (mmol/L) & -1.685 & 0.194 & -4.234 & 0.864 \\
\hline HDL-C (mmol/L) & $1.53 \mathrm{I}$ & 0.229 & -0.972 & 4.034 \\
\hline LDL-C (mmol/L) & $\mathrm{I} .887$ & 0.146 & -0.662 & 4.437 \\
\hline TG (mmol/L) & 1.493 & 0.008 & 0.397 & 2.589 \\
\hline Constant & -2.526 & 0.056 & -5.122 & 0.070 \\
\hline
\end{tabular}

Abbreviations: BP, blood pressure; Cl, confidence interval; HDL-C, high-density lipoprotein cholesterol; LDL-C, low-density lipoprotein cholesterol; TG, triglyceride. 
Supplementary Table 3 Robust regression in Phase 2

\begin{tabular}{|c|c|c|c|c|}
\hline & Coefficient & $P$-value & 95\% lower $\mathrm{Cl}$ & $95 \%$ upper $\mathrm{Cl}$ \\
\hline Age & -0.016 & 0.192 & -0.040 & 0.008 \\
\hline \multicolumn{5}{|l|}{ Sex } \\
\hline Male & Reference & - & - & - \\
\hline Female & 0.663 & 0.024 & 0.089 & 1.238 \\
\hline \multicolumn{5}{|l|}{ Race } \\
\hline Chinese & Reference & - & - & - \\
\hline Malay & 0.348 & 0.326 & -0.349 & 1.046 \\
\hline Indian & 1.206 & 0.000 & 0.551 & 1.862 \\
\hline \multicolumn{5}{|l|}{ Smoking status } \\
\hline Nonsmokers & Reference & - & - & - \\
\hline Smokers & 0.294 & 0.504 & $-0.57 \mathrm{I}$ & 1.158 \\
\hline \multicolumn{5}{|l|}{ SE status } \\
\hline SE private & Reference & - & - & - \\
\hline SE subsidized & 0.309 & 0.332 & -0.317 & 0.936 \\
\hline BMI & 0.101 & 0.000 & 0.047 & 0.154 \\
\hline Systolic BP (mmHg) & 0.004 & $0.58 \mathrm{I}$ & -0.012 & 0.021 \\
\hline Diastolic BP (mmHg) & 0.007 & 0.640 & -0.023 & 0.037 \\
\hline HbAlc (\%) & 0.056 & 0.532 & -0.120 & 0.231 \\
\hline Cholesterol (mmol/L) & 0.433 & 0.704 & -1.807 & 2.673 \\
\hline HDL-C (mmol/L) & -0.212 & 0.880 & -2.968 & 2.545 \\
\hline LDL-C (mmol/L) & -0.325 & 0.774 & -2.547 & 1.897 \\
\hline TG (mmol/L) & 0.169 & 0.760 & -0.919 & 1.257 \\
\hline Aspirin & 0.015 & 0.958 & -0.559 & 0.590 \\
\hline Statin & -0.022 & 0.951 & -0.727 & 0.683 \\
\hline ACE/ARB & 0.084 & 0.775 & -0.494 & 0.662 \\
\hline Rosiglitazone & -0.049 & 0.919 & -1.006 & 0.907 \\
\hline Metformin & -1.035 & 0.002 & -1.695 & -0.375 \\
\hline Sulfonylurea & 0.429 & 0.159 & -0.170 & 1.027 \\
\hline Insulin & 0.171 & 0.628 & -0.524 & 0.865 \\
\hline Acarbose & -0.092 & 0.879 & -1.279 & 1.094 \\
\hline Glinides & -1.250 & 0.535 & -5.213 & 2.713 \\
\hline Constant & -3.829 & 0.030 & -7.287 & -0.372 \\
\hline
\end{tabular}

Abbreviations: $\mathrm{ACE} / \mathrm{ARB}$, angiotensin-converting enzyme/angiotensin receptor blockers; $\mathrm{BMI}$, body mass index; $\mathrm{BP}$, blood pressure; $\mathrm{Cl}$, confidence interval; $\mathrm{HbAlc}$ glycated hemoglobin; HDL-C, high-density lipoprotein cholesterol; LDL-C, low-density lipoprotein cholesterol; SE, socioeconomic status; TG, triglyceride.

\section{Publish your work in this journal}

Diabetes, Metabolic Syndrome and Obesity: Targets and Therapy is an international, peer-reviewed open-access journal committed to the rapid publication of the latest laboratory and clinical findings in the fields of diabetes, metabolic syndrome and obesity research. Original research, review, case reports, hypothesis formation, expert opinion and commentaries are all considered for publication. The manuscript management system is completely online and includes a very quick and fair peer-review system, which is all easy to use. Visit http://www.dovepress.com/testimonials.php to read real quotes from published authors. 